\title{
Erratum to: Usefulness and capability of three-dimensional, full high-definition movies for surgical education
}

\author{
M. Takano ${ }^{*}$, K. Kasahara ${ }^{2}$, K. Sugahara² ${ }^{2}$ A. Watanabe ${ }^{1}$, S. Yoshida ${ }^{1}$ and T. Shibahara ${ }^{1}$
}

\section{Erratum}

In the publication of this article [1], there is an error in the Reference section at reference 16 .

The error: 'de Heer Maier H. G, Ortac A, Kuijten J (2015) Capturing and displaying microscopic images used in medical diagnostics and forensic science using $4 \mathrm{~K}$ video resolution - an application in higher education. J Microsc 260:175-179' Should instead read: 'Maier H. de Heer, G, Ortac A, Kuijten J (2015) Capturing and displaying microscopic images used in medical diagnostics and forensic science using $4 \mathrm{~K}$ video resolution-an application in higher education. J Microsc 260:175-179'. This has now been included in this erratum.

\section{Author details}

'Department of Oral and Maxillaofacial Surgery, Tokyo Dental College, 101-0061, 2-9-18 Misakicho, Chiyoda-ku, Tokyo, Japan. ${ }^{2}$ Department of Oral Pathobiological Science and Surgery, Tokyo Dental College, Mihama-ku, Japan.

Received: 29 June 2017 Accepted: 29 June 2017

Published online: 16 August 2017

\section{Reference}

1. Takano M, Kasahara K, Sugahara K, Watanabe A, Yoshida S, Shibahara T (2017) Usefulness and capability of three-dimensional, full high-definition movies for surgical education. Maxillofac Plast Reconstr Surg 39:1. doi:10.1186/s40902-017-0107-3

\footnotetext{
* Correspondence: takano@tdc.ac.jp

'Department of Oral and Maxillaofacial Surgery, Tokyo Dental College,

101-0061, 2-9-18 Misakicho, Chiyoda-ku, Tokyo, Japan
} 